\title{
Melez Mısır Islahında In-Vivo Katlanmış Haploid Tekniğinde Kullanılan Farklı Inducer Genotiplerin Haploid İndirgeme Oranların Belirlenmesi
}

\author{
*ibrahim CERIT ${ }^{1}$ Gönül CÖMERTPAY ${ }^{1}$ Rüstem OYUCU ${ }^{1}$ Bülent ÇAKIR ${ }^{1}$ \\ Rüştü HATIPOĞLU² Hakan ÖZKAN² \\ ${ }^{1}$ Doğu Akdeniz Tarımsal Araştırma Enstitüsü Müdürlüğü, Adana \\ ${ }^{2}$ Çukurova Üniversitesi Ziraat Fakültesi Tarla Bitkileri Bölümü, Adana \\ *Sorumlu yazar e-posta (Corresponding author; e-mail): ibrahimcerit@hotmail.com
}

Öz

Bu çalışma melez mısır ıslahında in-vivo katlanmış haploid hatların elde edilmesi çalışmasında kullanılan farklı induzer genotiplerin haploid indirgeme oranlarının tespit edilmesi amacıyla 2014 yılında Doğu Akdeniz Tarımsal Araştırma Enstitüsü'nde yürütülmüştür. Çalışmada induzer olarak (haploid indirgeyici ve toz verici) RWS, RWK-76 hatları ile bu hatların melezi olan RWS X RWK-76 melezi ve Stock-6 hattı kullanılmıştır. Haploid tohum elde etmek amacıyla ana (toz alıcı) olarak, toplamda 75 farklı genotip kullanılmıştır. Bunlardan 66'sını Doğu Akdeniz Tarımsal Araştırma Enstitüsü mısır ıslah çalışmaları kapsamında elde edilen $F_{2}$ kademesindeki materyal, 9'unu ise ticari hibrit çeşitlerin açıkta tozlanması ile elde edilen populasyonlardan seçilen 9 farklı genotip oluşturmuştur. Induzer olarak kullanılan genotiplerin haploid indirgeme oranları çalışmada ana (toz alıcı) olarak kullanılan genotiplere göre değişiklik göstermiştir. Ana olarak kullanılan 75 genotipten 69'undan toplam 1463 adet haploid tohum alınmıştır. Haploid tohumların seleksiyonu renk markörüne göre yapılmıştır. En yüksek haploid tohum oranı \%7.80 ile induzer olarak kullanılan RWK-76 hattından elde edilmiştir. En düşük haploid tohum oranı ise \%1.28 ile induzer Stock-6 hattından alınmıştır. Yapılan çalışmada ortalama haploid tohum elde etme oranı \%4.79 olarak saptanmıştır.

Anahtar Kelimeler: Mısır, Islah, induzer hat, haploid

\section{Determination of Haploid Induction Rates of Different Inducer Lines Used for In-Vivo Double Haploid Technique in Hybrid Maize Breeding}

\begin{abstract}
This research was conducted to determine haploid induction rate (HIR) of different inducer lines used for in-vivo double haploid technique in hybrid maize breeding at the East Mediterranean Agricultural Research Institute. In the study RWS, RWK-76 inducer lines, their cross RWS X RWK-76 and Stock-6 were used as male parent for haploid induction. In the study 75 different $F_{2}$ genotypes as female parent were used for haploid seed production. The 66 of $\mathrm{F}_{2}$ genotypes were selected from the corn breeding material of East Mediterranean Agricultural Research Institute, and 9 genotypes were selected from open pollinated populations of the commercial hybrid cultivars. Results of the study showed that haploid induction rate of different inducer genotypes changed depending on the female parent. It was obtained 1463 haploid seeds from $69 \mathrm{~F}_{2}$ genotypes of total $75 \mathrm{~F}_{2}$ genotypes. The highest haploid induction rate $(7.8 \%)$ was obtained from the inducer RWK-76 line, while the lowest haploid induction rate $(1.28 \%)$ was obtained from the stock-6, and average haploid induction rate (HIR) was $4.79 \%$.
\end{abstract}

Keywords: Maize, breeding, inducer line, haploid

Giriş

$\mathrm{M}$ Isır, insan ve hayvan beslenmesinde, ayrıca endüstride ham madde olarak kullanılan önemli bir tahıl bitkisidir. Türkiye'de mısırın ekim alanı 2014 yılı itibariyle 658645 ha, üretimi 5.950 milyon ton ve verim 907 kg/da'dır (TUIK 2014).
Ülkemizde hibrit mısır tohumluğunun yaklaşık \%95'ini yabancı çeşitler oluşturmakta, yerli çeşitlerimizin payı \%5’i geçmemektedir. Bundan dolayı yabancı çeşitler için her yıl yurtdışına önemli oranda royalite bedeli ödenmektedir. 
Klasik bitki ıslahı hem genetik faktörler hem de çevresel koşullar etkisinde olduğundan sonuca ulaşmak çok uzun zaman almaktadır. Bitki türüne göre değişmekle beraber bir çeşidin ıslah edilebilmesi yaklaşık 10 ile 14 yıl sürmektedir. Mısır bitkisinde yüksek verimli ve kaliteli hibritlerin geliştirilmesi için sürekli olarak yeni saf hatların geliştirilmesi gerekir. Kendilenmiş hat geliştirme, melez mısır ıslah programlarının temel konusudur. Geleneksel metotlarla bu saf hatların elde edilmesinde en az 6-7 yıl süreye intiyaç duyulmakta ve bu sürenin sonunda yine de $\% 100$ homozigotluk düzeyine ulaşmak mümkün olmamaktadır. Dolayısıyla bitki ıslahçıları bu süreci kısaltmak için yeni teknolojilere başvurmuşlardır. Bu sürenin kısaltılmasında haploid bitki elde etme teknikleri önemli avantajlar sağlamaktadır. Mısır ıslahında haploid tekniği ile elde edilen katlanmış haploid hatların potansiyeli uzun süre önce ortaya konmuştur (Chase 1969). Mısır ıslah çalışmalarında haploid bitki elde etme tekniklerinin kullanılmasıyla kısa sürede $\% 100$ homozigot hatlar elde edilebilmekte ve böylece ıslah çalışmalarında ıslah süreci kısalmakta, ıslah çalışmalarının hızlı ve güvenilir bir şekilde etkinliği artmaktadır. Ayrıca haploid bitki elde etme teknikleri kullanılarak ıslah çalışmalarında sonuca çok daha kısa ve etkin bir şekilde ulaşılmasıyla maliyetin düşürülmesi açısından da önemli avantajlar sağlanabilmektedir.

Haploid bitkiler in-vitro ve in-vivo olarak elde edilebilmektedir. In-vitro haploid bitki elde etme teknikleri laboratuar şartlarında örneğin, anter veya mikrospor kültürü, polenlerin farklı derecelerde sıcaklığa maruz bırakılarak haploid bitkilerin elde edilmesi (Mathur ve ark. 1980), polenlerin ışınlanması (Mathur ve ark. 1976), koçan püsküllerine maleichydracide uygulaması (Zuoyo and Mingguang 1984) ve çeşitli herbisitlerin uygulanması şeklinde yapılmaktadır. Ancak bu tür in-vitro uygulamalarda genotip etkisi nedeniyle yeterli oranda sonuç alınamamaktadır. Ticari olarak geliştirilen mevcut katlanmış hatların bir çoğunun in-vivo haploid tekniği ile elde edildiği, diğer tekniklerin ise katlanmış hat geliştirmede daha az etkili olduğu bildirilmektedir (Geiger and Gordillo 2009). In-vivo haploid bitki elde etme tekniğinde son yıllarda geliştirilen ve induzer olarak adlandırılan hatlar kullanılmaktadır. Induzer hatlar tozlayıcı olarak kullanılmakta ve spantone bir şekilde toz verdiği bitkinin koçanlarında haploid olan tohumların oluşmasına imkan vermektedir. Bu haploid tohumlar selekte edilerek çimlendirilmekte, çimlenen tohumlara kolchisin uygulamasıyla kromozom katlaması gerçekleşmekte ve sonuçta \%100 homozigot fertil katlanmış haploid hatlar elde edilebilmektedir (Geiger ve Gordillo 2009). Invivo tekniği ile haploid bitki elde etmede "maternal" ve "paternal haploidi" olmak üzere iki yöntem kullanılmakta olup, Induzer hattın polinatör yani baba olarak kullanılması yöntemine maternal haploidi, Inducer hattın toz alıcı yani ana olarak kullanılması yöntemi ise paternal haploidi olarak ifade edilmektedir (Coe1959; Kermicle 1969). Maternal haploid yöntemi ile elde edilen haploid oranı, paternal haploid yöntemine göre daha yüksek olmaktadır (Lashermes and Beckert 1988). Başlangıçta maternal haploid tekniğinde donör olarak kullanılan Induzer hatların haploid bitki oluşturma oranı \%0.1 iken, "Stock 6" olarak adlandırılan ve günümüzdeki İnduzer hatların babası olarak nitelenen hattan geliştirilen modern Induzer hatlar ile bu oran \%6-14'e kadar yükselmiştir (Coe 1959; Geiger, 2011). Nitekim Hohenheim Üniversitesi'nde (Almanya) geliştirilen RWS ve RWK-76 adlı hatlar, son yıllarda geliştirilen en etkili İnduzer hatlardan olup, bu hatlar ılıman iklimlere adaptasyonu iyi olan hatlar olduğu gibi tropikal iklimlere de uyum sağlayabilen hatlardır. Bu Induzer hatlarının melezinden haploid tohum elde etme oranı yaklaşık \%8'dir (Röber et al. 2005). RWS ve RWK-76 Induzer hatları yanında bu hatların melezi olan RWS X RWK-76 melezi de Hohenheim Üniversitesi Bitki Islahı Enstitüsü'de geliştirilmiş olup, haploid bitki elde etmede kullanılmaktadır (Röber ve ark. 2005). RWS X RWK-76 melezinden haploid bitki elde edilme başarısı yaklaşık \%9-10'dur (Geiger and Gordillo, 2009). Donör olarak kullanılan İnduzer hatların haploid bitki elde etme başarılarında, önemli farklıııklar saptanmıştır. Bu başarı oranını, genotipin yanında çevresel faktörler, kullanılan metot ve toz verme zamanı da etkilemektedir (Röber et al. 2005; Rotarenco et al. 2009). RWS ve RWK-76'nın melezi olan $F_{1}$ 'in donör olarak kullanılması durumunda, hatlara göre daha güçlü bir yapı ve stres şartlarına daha toleranslı oldukları için, geniş ölçekli haploid bitki elde etme programlarında başarıyla uygulanabilmektedir (Geiger 2009). Yine haploid bitki elde etmede, izole bir alan içinde açıkta tozlama yöntemi yerine el ile tozlama yönteminde en iyi sonuç alınmaktadır (Geiger and Gordillo 2009). 
Haploid bitkinin tanımlanması; flowsitometre cihazı ile kromozom sayımı yönteminin kullanılarak yapılması yanında, R1-nj renk markörü yardımıyla da çok daha hızlı, basit ve ucuz bir şekilde de yapılabilmektedir. İnduzer hatlar ile yapılan tozlamadan sonra haploid tohumların seleksiyonunda; tohumun üst kısmında kırmızı renkliliği veren "red crown" veya "navajo" olarak tanımlanan dominant antosiyanin pigmentinin ifadesini düzenleyen markör geni ile rahatlıkla ayırt edilebilmektedir (Röber et al. 2005). İnduzer hatlar ile başlangıç materyallerinin melezleme işleminden sonra elde edilen koçanlarda 3 farklı kategoride tohum oluşması beklenmektedir. Birinci kategoride yer alan renksiz embriyo ve renksiz endosperme sahip tohumlar kontaminasyondan dolayı yabancı toz almış olan haploid olmayan tohumlardır. Bu kategorideki tohumlar çok az bir orana sahiptir. İkinci kategoride yer alan mor renkli embriyo ve mor renkli endosperme sahip tohumlar, induzer hat ile normal döllenme sonucu oluşmuş olan diploid tohumlardır. Bu kategorideki tohumlar toplamda en yüksek orana sahip tohumlardır. Üçüncü kategoride yer alan renksiz embriyo ve mor renkli endosperme sahip tohumlar ise haploid olarak kabul edilen tohumlardır (CIMMYT, 2010). Haploid olarak seçilen tohumlar $n=10$ kromozomlu yapıda olup, çimlendiklerinde fertil olmayan bitkileri oluştururlar Haploid tohumların 2n=20 kromozomlu fertil duruma gelebilmesi için kolchisin uygulaması ile kromozom katlaması yapılması gerekir. Bu işlem için değişik araştırıcılar farklı protokoller uygulamaktadır. Deimling et al. (1997) ve Gayen et al. (1994), sera şartlarında 2-3 gün süreyle $26^{\circ} \mathrm{C}$ 'de petrilerde çimlendirilme işlemine tabi tutulan haploid tohumların koleoptil uzunluğu 20-30 mm'ye ulaştığında \%0.06 kolchisin ve \%0.5 DMSO (dimethylsulfoxid) içeren çözeltide $18^{\circ} \mathrm{C}$ 'de, 12 saat süreyle muamele ettiklerinde suni olarak kromozom katlamada önemli başarı kaydetmişlerdir.

$\mathrm{Bu}$ çalışma in-vivo maternal haploid tekniğini kullanarak farklı induzer hatların Doğu Akdeniz Tarımsal Araştırma Enstitüsü Mısır ıslah çalışmaları kapsamında geliştirilen bazı materyallerdeki haploid indirgeme oranlarını belirlemek amacıyla yürütülmüştür.

\section{Materyal ve Yöntem}

$\mathrm{Bu}$ çalışma, Doğu Akdeniz Tarımsal Araştırma Enstitüsü Müdürlüğü araştırma arazisinde yapılmıştır. Çalışmada baba (toz verici) olarak RWS, RWK-76 induzer hatları ve bu hatların melezi olan RWS X RWK-76 melezi ve Stock-6 hattı kullanılmıştır. Ana (toz alıcı) olarak, Doğu Akdeniz Tarımsal Araştırma Enstitüsü mısır ıslah çalışmaları kapsamında elde edilen 66 adet $F_{2}$ açılan materyal ve 9 adet ticari çeşitin açıkta tozlanması ile elde edilen populasyonlardan seçilen materyal olmak üzere toplam 75 adet açılan materyali kullanılmıştır (Çizelge1).

$\mathrm{Bu}$ çalışmada haploid tohum elde etme çalışmasında, in-vivo maternal haploid tekniği kullanılmıştır. Melezleme işleminde bir sorun yaşanmaması için ana (toz alıcı) olarak kullanılan, açılan $F_{2}$ materyalleri ve baba (toz verici) olarak kullanılan Induzer hatların FAO olum gruplarına göre ekim zamanı ayarlanmıştır. Induzer hatların püskül verme dönemi ile ana $F_{2}$ 'lerin toz alma dönemi senkronizasyonunu garanti etmek için ana (toz alıcı) olarak kullanılan toplam 75 adet $F_{2}$ açılan materyalin ekimi 26/03/2014 ve 02/04/2014 olmak üzere 7 gün arayla iki farklı tarihte tekrarlanmıştır. Hohenheim Üniversitesi Bitki Islahı Enstitüsü'den getirtilen İnduzer RWS, RWK-76, Stock- 6 hatları ve RWS X RWK-76 melezinin ekimi ise 11/04/2014, $15 / 04 / 2014$ ve 24/04/2014 olmak üzere 3 farklı tarihte tekrarlanmıştır. Ana ve baba genotipler 5 metre uzunluğundaki sıralara, sıra üzeri mesafe $25 \mathrm{~cm}$ ve sıra arası $70 \mathrm{~cm}$ olacak şekilde ikişer sıra halinde ekilmiştir. Her iki sırada bir sıra boş bırakılarak melezleme yapılırken rahat hareket etme olanağı sağlanmıştır. Ana olarak kullanılacak genotiplerin her biri için 2 sırada toplam 42 bitki ve 2 ekim zamanında toplam 84 bitki yetiştirilmiştir. Induzer hatlar ile başlangıç materyali $F_{2}$ 'lerin melezleme işlemi Russel and Eberhart (1975)'in uyguladığı yönteme göre yapılmıştır. Melezleme işleminde Induzer genotipler baba (toz verici), $F_{2}$ melezler ana (toz alıcı) olarak kullanıımıştır. Melezleme işleminden önce ana olarak seçilen hatların koçanları, koçan püskülü çıkmadan önce pelür kağıt torbalarla kapatılarak toz alması önlenmiştir. Baba olarak ekilen Induzer genotiplerin tepe püskülleri kraft kağıt torba ile çiçek tozu dökmeye başlamadan hemen önce kapatılarak izole edilmiştir. İzole edilen baba hatların çiçek tozları, izole edilen ana hatlara koçan püskülü çıkmaya başlayınca verilerek tozlama işlemi gerçekleştirilmiştir. Baba (toz verici) olarak kullanılacak Induzer gentotiplerin her bir bitkisinden alınan polenler ana olarak kullanılan bitkilerden mümkün olduğu kadar fazla bitkiye verilmiştir. Melezlenmiş koçanlar kraft kâğıt torba ile hasada kadar izole durumda tutulmuştur. Induzer hatlar ile başlangıç 
materyallerinin melezleme işleminden sonra, tanelerin hasat olgunluğuna geldiği siyah nokta (black point) döneminde koçanlar, el ile hasat edilmiştir. Haploid tohumların seleksiyon yöntemi, R1-nj renk markörü yardımıyla, Röber et al. (2005) ve International Maize and Wheat Improvement Center (CIMMYT 2010)'in uyguladığı tekniğe göre yapılmıştır. Bu tekniğe göre, Induzer hatlar ile başlangıç materyallerinin melezleme işleminden sonra 3 farklı kategoride tohum oluşmuştur. Birinci kategoride renksiz embriyo ve renksiz endosperme sahip tohumlar, bunlar kontaminasyondan dolayı yabancı toz almış olan haploid olmayan tohumlardır. İkinci kategoride mor renkli embriyo ve mor renkli endosperme sahip tohumlar, bunlar da mor renkliliği tayin eden dominant genlerden dolayı mor renge sahip, ancak haploid olmayan tohumlardır. Üçüncü kategoride ise renksiz embriyo ve mor renkli endosperme sahip tohumlar olup, bunlar haploid olarak kabul edilen tohumlardır. Bu her üç kategorideki tohumlar ayrı ayrı tasnif edilerek (Şekil 1, 2, 3), üçüncü kategorideki haploid tohumların elde edilme oranları aşağıdaki formüle göre hesaplanmıştır. Haploid tohum oranı $(\%)=($ Haploid tohumlar/Hasat edilen toplam tohumlar) $\times 100$

Çizelge 1. Başlangıç materyali ana(toz alıcı) olarak kullanılan F2 açılan materyalin pedigrisi

Table 1. Pedigrees of F2 materials used as female parent in the in vivo haploid technique

\begin{tabular}{|c|c|c|c|c|c|}
\hline No & Pedigri & No & Pedigri & No & Pedigri \\
\hline 1 & $97 / 13 \times 2004 / 3223 \mathrm{~A}$ & 26 & 01/POP/1X00/315/A & 51 & SA2001/56X96/22A \\
\hline 2 & SA2001/19X2004/3223A & 27 & $96 / 5-K X 00 / 315 / A$ & 52 & $97 / 13 \times 96 / 22 A$ \\
\hline 3 & 01/POP/14BX2004/3223A & 28 & 01/POP/12A2KX00/315/A & 53 & SA2001/19X96/22A \\
\hline 4 & $96 / 5-K X 2004 / 3223 A$ & 29 & $96 / 13 \times 00 / 313 \mathrm{~B} 1$ & 54 & 01/POP/01X96/22A \\
\hline 5 & SA2001/1X2004/3223A & 30 & $96 / 16 \times 00 / 313 B 1$ & 55 & $96 / 5-K X 96 / 22 A$ \\
\hline 6 & 96/6-KX2004/3223A & 31 & SA2001/56X00/313B1 & 56 & $96 / 17 \times 96 / 22 A$ \\
\hline 7 & $97 / 8 B \times 2004 / 3223 \mathrm{~A}$ & 32 & $97 / 13 \times 00 / 313 \mathrm{~B} 1$ & 57 & 97/8BX00/313B1 \\
\hline 8 & $96 / 13 \times 2004 / 31 N 27$ & 33 & SA2001/19X00/313B1 & 58 & 01/POP/12A2X96/22A \\
\hline 9 & $97 / 13 \times 2004 / 31 N 27$ & 34 & 01/POP/01X00/313B1 & 59 & SA2001/1X01/POP/1 \\
\hline 10 & SA2001/19X2004/31N27 & 35 & 01/POP/14BX00/313B1 & 60 & 96/25X01/POP/1 \\
\hline 11 & 01/POP/01X2004/31N27 & 36 & 96/5-KX00/313B1 & 61 & 96/2501/POP/14B \\
\hline 12 & $96 / 5-K X 2004 / 31 N 27$ & 37 & SA2001/1X00/313B1 & 62 & 96/16X POP/14B \\
\hline 13 & $2001 / 1 X 2004 / 31 N 27$ & 38 & $96 / 6 \times 00 / 313 \mathrm{~B} 1$ & 63 & 97/13X POP/14B \\
\hline 14 & $96 / 6-K \times 2004 / 31 N 27$ & 39 & $96 / 17 \times 00 / 313 B 1$ & 64 & SA2001/56X POP/14B \\
\hline 15 & $96 / 17 X 2004 / 31 N 27$ & 40 & 97/8BX00/313B1 & 65 & $\mathrm{M} 1 \mathrm{X} 13$ \\
\hline 16 & $96 / 13 \times 2004 / 2004 / 32 D 99 A$ & 41 & 01/POP/12A2X00/313B1 & 66 & $\mathrm{M} 2 \mathrm{X} 9$ \\
\hline 17 & SA2001/19X2004/32D99A & 42 & $96 / 13 \times 00 / 315 B 1$ & 67 & 31P41(F2) \\
\hline 18 & 01/POP/1X2004/32D99A & 43 & $97 / 13 \times 00 / 315 B 1$ & 68 & $31 \mathrm{G} 98(\mathrm{~F} 2)$ \\
\hline 19 & 01/POP/14BX2004/32D99A & 44 & SA2001/19X00/315B1 & 69 & DKC6589(F2) \\
\hline 20 & 96/5-KX2004/32D99A & 45 & 01/POP/01X00/315B1 & 70 & SASA18(F2) \\
\hline 21 & SA2001/1X2004/32D99A & 46 & 01/POP/14BX00/315B1 & 71 & ES-CALIENTE(F2) \\
\hline 22 & 96/17X2004/32D99A & 47 & 96/5-KX00/315B1 & 72 & ES-VALERIA(F2) \\
\hline 23 & 01/POP/12A2KX2004/32D99A & 48 & SA2001/1X00/315B1 & 73 & DVF783(F2) \\
\hline 24 & $96 / 1300 / 315 / A$ & 49 & 01/POP/12A2X00/315B1 & 74 & ESVOLTI(F29) \\
\hline 25 & SA2001/19X00/315/A & 50 & $96 / 13 \times 96 / 22 A$ & 75 & NF6174(F2) \\
\hline
\end{tabular}

(1-66): Doğu Akdeniz Tarımsal Araştırma Enstitüsü Müdürlüğü, (67-75): Açıkta tozlanan ticari çeşitler

(1-66): East Mediterranean Agricultural Research Institute, (67-75): Open pollinated populations of the commercial hybrid cultivars

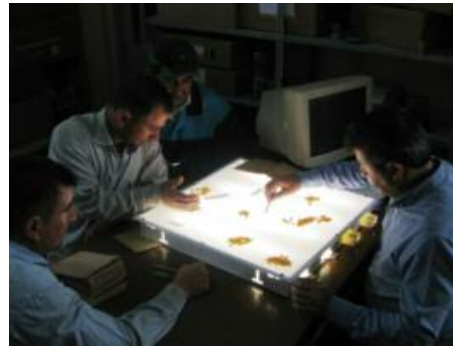

Şekil 1. Haploid tohumların seleksiyonunda kullanılan ışıklı düzenek

Figure 1. Illuminated apparatus used for the selection of haploid seeds

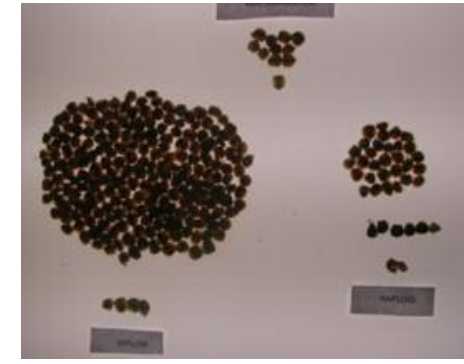

Şekil 2. Işıklı düzenekte tohumların görünümü

Figure 2. Seeds on illuminated apparatus

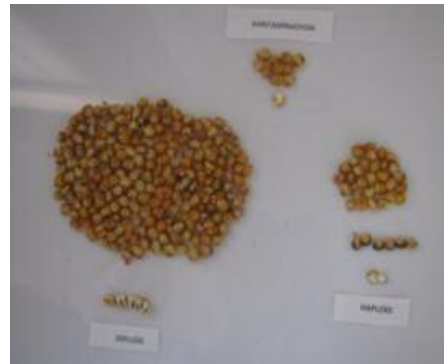

Şekil 3. Haploid, diploid ve kontamine olmuş tohumlar

Figure 3. Haploid, diploid and contaminated seeds 


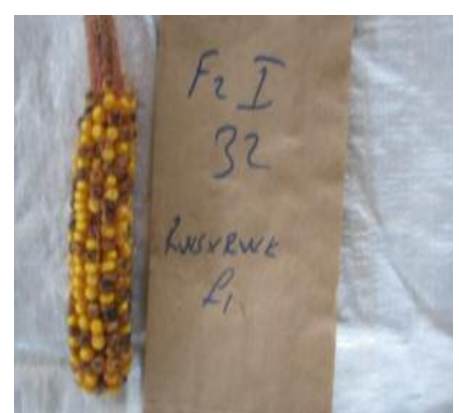

Şekil 4. RWSXRWK-76 ile $F_{2}$ açılan genotipin melezinin koçan görünümü

Figure 4. Ear of a $F_{2}$ genotype pollinated by RWS $X$ RWK-76

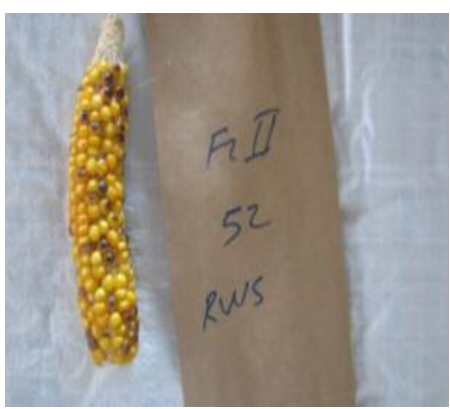

Şekil 5. RWS ile $F_{2}$ açılan genotipin melezinin koçan görünümü

Figure 5. Ear of a $F_{2}$ genotype pollinated by $R W K-76$

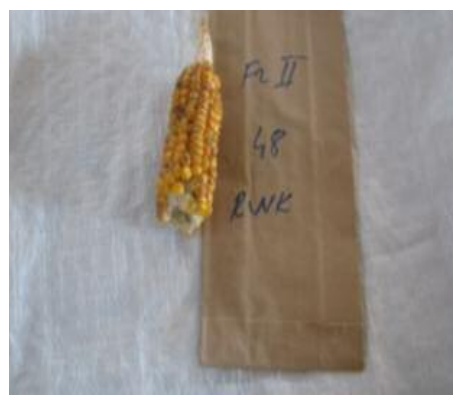

Şekil 6. RWK-76 ile $F_{2}$ açılan genotipin melezinin koçan görünümü

Figure 6. Ear of a $F_{2}$ genotype pollinated by RWK-76

Çizelge 2. Başlangıç materyali ana (toz alıcı) olarak kullanılan genotipler ile baba(toz verici) olarak kullanılan induzer genotiplerin melezinden elde edilen haploid tohum sayısı

Table 2. Number of haploid seeds from differant inducer lines

\begin{tabular}{lccccc}
\hline \multicolumn{1}{c}{ Inducer } & $\begin{array}{c}\text { Haploid Tohum } \\
\text { (Adet) }\end{array}$ & $\begin{array}{c}\text { Diploid Tohum } \\
\text { (Adet) }\end{array}$ & $\begin{array}{c}\text { Kontaminasyon } \\
\text { (Adet) }\end{array}$ & HIR (\%) & $\begin{array}{c}\text { TOPLAM } \\
\text { (Adet) }\end{array}$ \\
\hline RWS & 271 & 2886 & 716 & 7.00 & 3873 \\
RWK-76 & 246 & 2841 & 69 & 7.80 & 3156 \\
RWS X RWK-76 & 397 & 10302 & 2707 & 3.06 & 13009 \\
Stock-6 & 549 & 39717 & 2605 & 1.28 & 42875 \\
\hline Toplam & 1463 & 55746 & 6097 & 4.79 & 62913 \\
\hline
\end{tabular}

\section{Bulgular ve Tartışma}

Başlangıç materyali ana (toz alıcı) olarak kullanılan genotipler ile baba (toz verici) olarak kullanılan induzer genotiplerin melezlenmesinden elde edilen haploid tohumların sayısı genotiplere göre değişiklik göstermiştir (Şekil 4, 5 ve 6). Ana olarak kullanılan 75 genotiptin 69'undan haploid tohum alınmış, 6 genotipte alınamamıştır. Haploid bitki elde etmek için induzer genotiplerle yapılan melezlemeden elde edilen haploid tohum sayıları Çizelge 2'de verilmiştir

Çizelge 2'de görüldüğü gibi ana(toz alıcı) olarak kullanılan genotiplerin 4 farklı induzer hatlarla melezinden toplam 62.913 adet tohum elde edilmiştir. Yapılan melezlemelerden renk markörüne göre 1463 adet haploid tohum selekte edilmiştir. Diploid tohum sayısı 55.746, kontaminasyon ise 6.097 adet olarak gerçekleşmiştir. En yüksek haploid tohum oranı \%7.80 ile induzer olarak kullanılan RWK-76 hattından elde edilmiştir. En düşük haploid tohum oranı ise \%1.28 ile induzer Stock-6 hattından alınmıştır. Induzer RWS hattından $\% 7.00$ ve RWSXRWK-76 induzer melezinden ise \%3.06 oranında haploid tohum elde edilmiştir. RWSXRWK-76 induzer melezinin haploid tohum oluşturma oranının beklenenden düşük çıkmasının nedeni, çalışmada ana (toz alıcı) olarak kullanılan bazı materyallerin çiçeklenme sürelerinin senkronizasyondan kaynaklanmış olabilir. Ortalama haploid tohum elde etme oranı $\% 4.79$ olarak saptanmıştır.

\section{Sonuç}

Renk markörüne göre yapılan seleksiyona göre en yüksek haploid tohum oranı RWK-76 induzer hattında $\% 7.80$ olarak elde edilirken, en düşük haploid tohum oranı ise \%1.28 ile induzer Stock-6 hattından alınmıştır.

\section{Teşekkür}

Bu araştırma Türkiye Bilimsel ve Teknolojik Araştırma Kurumu (TUBITAK) tarafından desteklenmiştir (Proje No: 1130916).

\section{Kaynaklar}

CChase S.S., 1969. Monoploids and Monoploid Derivatives of Maize (Zea mays L.). Bot. Review, 35: 117-167

CIMMYT, 2010. http://www.youtube.com/watch?v=V 2jOEuZjjrg

Coe E.H., 1959. A Line of Maize with haploid frequency. Am. Nat. 93:381-382

Deimling S., Röber F. and Geiger H.H., 1997. Methodik Und Genetik Der In-Vivo-Haploiden İnduktion Bei Mais. Vortr Pflanzenzüchtg. 38: 203-224 
Gayen P., Madan J.K., Kumar R. and Sarkar K.R., 1994. Chromosome Doubling in Haploids Through Colchicine. Maize Genet. Coop. Newsletter 68: 65

Geiger H.H., 2009. Doubled Haploids. In: J.L. Bennetzen, S. Hake (Eds.), Maize Handbook. Vol. II: Genetics and Genomics. Springer Verlag, Heidelberg, New York, pp. 641-659

Geiger H.H., 2011. In vivo Haploid Techniques, Melez Mısırla 100 Yıl Çalıştayı Özet Kitapçığı, 18-20 Mart 2011, Antalya

Geiger H.H. and Gordillo G.A., 2009. Doubled haploids in hybrid maize breeding. Maydica, 54: 485-499

Kermicle J.L., 1969. Androgenesis conditioned by a mutation in maize. Science, 166: 1422-1424

Lashermes P. and Becekert M., 1988. Genetic Control of maternal haploidy in maize (Zea mays L.) and selection of haploid Inducing lines. Theor. Appl. Genet., 76: 405-410

Matur M.A. and Sarkar K.R.,1980. Induction of maternal haploids in maize through heat treatment of polen. Curr Sci., 49: 744-746
Mathur D.S., Sachan J.K.S. and Sarkar K.R., 1976. Radiation induced haploid and heterofertilization in maize. J. Nucl. Agric. Biol., 5: 76-77

Rotarenco V.A., Dicu G., Sarmanuic M., 2009. Induction of Maternal Haploids in Maize. Maize Genet. Coop. Newsletter 83 (http://www.agron.missouri.edu/mnl/83/46rota renco.htm)

Röber F.K., Gordillo G.A. and Geiger H.H., 2005. In vivo haploid induction in maize - performance of new inducers and significance of doubled haploid lines in hybrid breeding. Maydica, 50: 275-283

Russel W.A., Eberhart S.A., 1975. Hybrid performance of selected maize lines from reciprocal recurrent and testcross selection programmes. Crop Sci., 15: 1-4

TÜIK.2014. Türkiye İstatistik Kurumu, http://www.tuik.gov.tr

Zuoyo Z. and Minguang G., 1984. Production of pure lines of maize through parthenogenesis Induced by chemicals. Acta Genet. Sin., 11: $39-46$ 